\title{
Análise da Efetividade e da Razão Ótima do Hedge do Boi Gordo e do Cross-Hedge do Bezerro no Estado de São Paulo (2001 a 2010)
}

\section{Analysis of Effectiveness and Optimal Ratio of Hedge of Cattle and Cross-Hedge of Calf in the State of São Paulo (2001 to 2010)}

Clailton Ataídes de Freitas* William Bottega Alves**

Resumo: O trabalho tem por objetivo avaliar a efetividade de uma operação de hedge do boi gordo e de cross-hedge do bezerro no estado de São Paulo como forma de minimizar riscos, utilizando dados referentes ao período de 2001 a 2010. Para tanto, avaliou-se a possibilidade de utilização do mercado futuro da BMEFF-Bovespa, através do uso de contratos futuros de boi gordo. Nesse sentido, foram estimados três modelos econométricos: o risco de base do preço para os criadores de boi gordo e de bezerro, a razão ótima de hedge e cross-hedge e a efetividade dos mesmos. Os resultados obtidos pelo primeiro modelo apontaram um risco muito mais elevado para o bezerro vis-à-vis ao do boi gordo. Quanto ao segundo modelo, verificou-se uma razão hedge elevada do boi gordo e uma extremamente baixa para o bezerro. Já para a efetividade, obteve-se um percentual de proteção considerado bom em relação ao boi gordo e baixo para o bezerro.

Palavras-chave: Mercado futuro. Risco de base. Contratos futuros.

Abstract: The present study aims to evaluate the effectiveness of a hedge operation of cattle and cross-hedge of calf in the state of São Paulo, in order to minimize risks, using data from the period of 2001 to 2010 . To achieve this, the possibility of using the future market of BMEF was analyzed, through the use of future cattle contracts. Accordingly, three econometric models were estimated: the baseline risk for breeders of cattle and calf, the optimal hedge ratio and cross-hedge and their

\footnotetext{
* Doutor em Economia Aplicada pela Universidade de São Paulo (USP). Professor do Departamento de Ciências Econômicas e do Programa de Pós-Graduação em Economia e Desenvolvimento da Universidade Federal de Santa Maria (UFSM).E-mail: caf@ccsh.ufsm.br

* * Bacharel em Ciências Econômicas pela Universidade Federal de Santa Maria (UFSM). Gerente de Contas do Banrisul. E-mail: will_b_alves@hotmail.com
} 
effectiveness. The results obtained from the first model showed a much higher risk for the calf in comparison to the cattle. On the second model, there was a high ratio for the cattle and an extremely low ratio for the calf, as for the effectiveness, a good percentage of protection was obtained for the cattle and a low percentage was obtained for the calf.

Keywords: Future market. Baseline risk. Future contracts.

JEL Classification: G13; C32; Q14.

\section{Introdução}

O Brasil, atualmente, tem o maior rebanho bovino comercial do mundo, perdendo em quantidade somente para a Índia, onde o gado é considerado sagrado e, desde 2004, ocupa o posto de maior exportador mundial de carne bovina. Assim, a pecuária desempenha um papel de grande relevância econômica no país, pois, primeiro, a carne bovina é uma das principais fontes de alimentos do brasileiro; segundo, é uma importante geradora de divisas e; terceiro, é considerada um importante produto agropecuário em quase metade das unidades da federação. Cabe ressaltar que a exploração dessa atividade no país, de um modo geral, segue o modelo extensivo de criação, apesar de haver unidades produtivas com alto nível de tecnificação. ${ }^{1}$

Dois fatores são considerados cruciais para que essa atividade tenha alcançado tamanha expressividade econômica no Brasil, a saber: a sua extensão territorial e as suas condições edafoclimáticas. Apesar dessa conjunção de fatores favoráveis, essa atividade, como qualquer outra, expõe seus agentes ao risco de variação de preços. $^{2}$

Outro evento que expõe a pecuária bovina brasileira a riscos, de acordo com Silveira (2002), deve-se ao fato de a maior parte do sistema de produção, constituída pelas etapas de cria, recria e engorda, ser horizontal. Isso significa a especialização do produtor em uma ou duas dessas fases, ficando dependente da dinâmica das etapas a montante e a jusante. Nesse sistema de produção, a circulação dos animais é mais intensa, o que acarreta aumento dos custos de produção do boi gordo.

Devido ao perfil dessa atividade - com o produtor exercendo uma ou duas fases do processo de forma especializada - tem-se uma circulação intensa do bezerro. Por esse motivo, o preço desse produto se transforma em uma variável

\footnotetext{
$\overline{1}$ O leitor interessado pode obter mais informações em: $<$ http://www.nftalliance.com.br/gestao-de-risco-na-pecuária-intensiva/> . Acesso em: 4 mar. 2010.

2 Ver Gonçalves et al. (2008) e Oliveira et al. (2006).
} 
fundamental em todos os elos dessa cadeia. Esse também é o entendimento de Schouchana e Caffagni (2001), ao salientar que o risco de preço para esses pecuaristas envolve a relação de troca entre o boi gordo e o bezerro.

Assim, qualquer avaliação de risco de preços no mercado do boi gordo deve contemplar a relação de preços no mercado do bezerro. Contudo, não existe contrato futuro negociado na Bolsa de Mercadoria $\mathcal{E}$ Futuros (BMEF-Bovespa) do bezerro. Isso leva os hedgers, que tencionam minimizar o risco no mercado do boi gordo, a buscar alternativas para se proteger das alterações não esperadas nos preços do bezerro. Uma possibilidade efetiva é utilizar uma ferramenta chamada cross-hedge. De acordo com a BMËF (1998), uma operação de cross-hedge utiliza contratos futuros de um ativo diferente do possuído em estoque para proteger uma posição à vista quando não há contrato futuro correspondente ao ativo que está exposto ao risco, nesse caso, o bezerro. Sendo assim, essa operação gera um risco duplo, referente aos movimentos na diferença entre os preços à vista e futuro do produto especificado no contrato e aos movimentos na diferença entre os preços à vista do ativo sob operação de hedge e do ativo contratado.

As análises dessas operações no mercado futuro da BMEF-Bovespa tornaram-se cada vez mais seguras e eficientes. Isso se deve à abertura comercial, ocorrida na década de 1990, em vários países do mundo e, principalmente, no Brasil, que, aliada ao aumento expressivo na circulação de recursos financeiros entre os países - fruto da revolução tecnológica surgida com a internet -, geraram grande aumento das negociações nas bolsas de valores e mercadorias. Esse mercado, que ainda está em expansão, estabelece-se como um meio de os produtores rurais dos mais diversos setores protegerem-se dos riscos de preços inerentes às suas atividades.

Apesar do crescimento do mercado futuro no Brasil, ainda existem poucas commodities com contratos negociados nos pregões da BMEF-Bovespa. A possibilidade de uso desse recurso como meio de minimizar riscos se restringe a essas commodities, deixando muitos ramos de atividade agropecuária brasileira à margem dessa possibilidade. Para esses produtores, caso desejem reduzir os riscos de preços, via mercado de capital, resta a possibilidade de operar através de cross-hedge, o qual, por sua própria natureza, possui um risco de base muito maior que o own hedge. ${ }^{3}$ Nesse sentido, apesar de a pecuária bovina de corte ser uma importante atividade do agronegócio brasileiro, esta não possui instrumentos adequados nessa bolsa para proteção dos diferentes níveis de sua cadeia produtiva.

No Brasil, existem alguns estudos relacionados à razão ótima e efetividade do hedge do boi gordo. Entre eles, têm-se os estudos de Silveira (2002), que estimou

Considera-se own hedge quando se negocia contratos futuros da mesma característica do ativo físico possuído pelo operador.

FREITAS, C. A.; ALVES, W. B. Análise da Efetividade e da Razão Ótima do Hedge do Boi... 
a razão ótima e a efetividade do hedge do boi gordo e do cross-hedge do bezerro para diversas praças formadoras de preços, incluindo regiões do Paraná, Minas Gerais e São Paulo, com dados mensais de 1995 a 2001; de Gonçalves et al. (2008) que, além de estimarem a efetividade do hedge do boi gordo, estudaram a relação entre os preços à vista e futuro para o estado do Paraná, com dados mensais de 2001 a 2006; e, por fim, de Oliveira Neto e Figueiredo (2009), que estimaram a razão ótima de hedge do boi gordo para o estado de Goiás, entre 1997 a 2007 (dados mensais).

Além dos supracitados, outros estudos acerca da metodologia proposta foram desenvolvidos no Brasil, como Silva (2001), que examinou a viabilidade de se utilizar o contrato de soja em grão da BMËF-Bovespa como forma de gerenciar o risco dos agentes envolvidos na comercialização de grãos de soja e derivados ou, alternativamente, utilizar o hedge na Chicago Board of Trade (CBOT); o estudo de Gonçalves et al. (2008), que analisou a relação entre os preços futuro e à vista do boi gordo, estimou a efetividade do hedge do boi gordo e a direção da causação de preços, no sentido Granger, para a região do noroeste do Paraná; e a abordagem de Tonin, Braga e Coelho (2009) sobre a efetividade do hedge do milho com contratos futuros da BMËF-Bovespa para a região de Maringá.

O presente estudo se diferencia dos citados anteriormente em dois pontos principais, a saber: primeiro, utiliza-se os preços médios do boi gordo do estado de São Paulo e, não, de praças específicas como as estudadas por Silveira (2002); segundo, são utilizados dados a partir da última alteração ocorrida nos contratos de boi gordo da BMËF-Bovespa, quando passou a ser cotado em reais por arroba e não mais em pontos por arroba líquida, quando cada ponto correspondia à taxa de câmbio de reais por dólar. Assim, a consecução deste estudo possibilita diagnosticar, a partir das novas informações da base de dados, o nível de efetividade do hedge do boi gordo e do cross-hedge do bezerro, após a alteração dos contratos.

Com o propósito de dimensionar a atividade pecuária de grande porte de São Paulo, frente ao Brasil, cabe citar alguns números de 2010. O efetivo de bovinos no Brasil, segundo o IBGE, era de 209.541.109 cabeças. São Paulo, com 11.197.697 cabeças, responde por 5,3\% desse total, o que o coloca como oitavo produtor no país. Mato Grosso era e continua sendo o detentor do maior rebanho bovino brasileiro, responsável por $13,7 \%$ desse total. ${ }^{4}$

$\mathrm{Na}$ maioria dos trabalhos acerca da efetividade do hedge, os autores obtêm estimativas consideradas boas quanto à proteção aos riscos de preços das diversas atividades agrícolas desenvolvidas no Brasil. Já para o cross-hedge, em geral, chega-se à conclusão de que essa ferramenta não é efetiva para tal proteção.

$4 \quad$ Disponível em: < http://www.ibge.gov.br/home/estatistica/economia/ppm/2010/ppm2010.pdf>. Acesso em: 2 jan. 2013. 
Diante dessa problemática, propõe-se responder a seguinte questão: qual a real eficiência das operações de hedge e cross-hedge como forma de proteção, dos produtores de boi gordo e bezerro no estado de São Paulo, ao risco existente em suas atividades econômicas?

Para responder a essa problemática, delineia-se como objetivo geral analisar a eficiência do cross-hedge do bezerro no mercado futuro do boi gordo da BMEFF-Bovespa como meio de proteção aos riscos de preço aos quais os pecuaristas estão expostos. Como objetivos específicos, pretende-se calcular o risco de base, tanto nas operações de cross-hedge dos preços do bezerro na semana de vencimento do contrato futuro de boi gordo da BMËF-Bovespa, quanto nas operações de hedge do preço do boi gordo na mesma instituição, e analisar a razão ótima do cross-hedge e a efetividade dessa operação, assim como da operação de hedge, levando em conta o período de safra e entressafra.

Este artigo está organizado em cinco seções: a primeira é constituída por esta introdução; a segunda explicita o referencial teórico e metodológico que embasa todos os modelos aqui utilizados; a terceira traz a metodologia e os procedimentos econométricos utilizados para obter os resultados desejados e, também, a fonte e a base de dados; na quarta têm-se os resultados obtidos na pesquisa e as análises a respeito destes; e, por último, na quinta são apresentadas as conclusões a respeito da viabilidade e efetividade de aplicação das ferramentas estudadas.

\section{Referencial Teórico e Metodológico}

O conteúdo a seguir apresenta resumidamente a teoria do portfólio, a qual serve como base para a estimação e análise da razão ótima e da efetividade, tanto do hedge quanto do cross-hedge.

Fundamentalmente, a premissa básica dessa teoria é a de agentes que desejam maximizar os retornos em operações financeiras incorrendo em menores riscos possiveis. Para isso, define-se uma carteira ótima para um agente e se analisa o trade-off existente entre o retorno esperado e o risco do portfólio - medido pela variância do retorno dessa carteira. Pressupõe-se, também, que os agentes são avessos ao risco. Assim, o hedge, quando for avaliar as diferentes opções de investimentos, prefere aqueles que combinam concomitantemente maior retorno esperado e menor risco. Entre os autores que se destacam na proposição dessa teoria estão Markowitz (1952) e Sharpe (1964). Contudo, outros autores tiveram contribuições relevantes, como Johnson (1960), Ederington (1979) e Myers e Thompson (1989).

Com base nos estudos de Markowitz (1952) e Johnson (1960), pode-se demonstrar que a receita obtida por um hedge de venda é decomposta em: ${ }^{5}$

Todo o conteúdo apresentado no restante desta seção foi baseado em Johnson (1960) e Markowitz (1952), porém adaptado aos interesses do presente estudo.

FREITAS, C. A.; ALVES, W. B. Análise da Efetividade e da Razão Ótima do Hedge do Boi... 


$$
Y_{t}=q_{v}\left(\mathrm{P}_{v t}-\mathrm{P}_{v t-1}\right)+q_{f}\left(\mathrm{P}_{f t-1}-\mathrm{P}_{f t}\right)
$$

em que, $Y_{t}$ é a receita do hedger em um momento; $t, q_{v}$ e $q_{f}$ são, respectivamente, os volumes das posições assumidas nos mercados à vista e futuro da commodity em questão; $\left(\mathrm{P}_{v t}\right.$ e $\left.\mathrm{P}_{v t-1}\right)$ e $\left(\mathrm{P}_{f t}\right.$ e $\left.\mathrm{P}_{f t-1}\right)$ são os preços da commodity nos mercados à vista e futuro, respectivamente, cotados em dois momentos do tempo.

De forma equivalente, a equação 1 é dada por:

$$
Y_{t}=q_{v}\left(\mathrm{P}_{v t}-\mathrm{P}_{f t-1}\right)-q_{f}\left(\mathrm{P}_{f t}-\mathrm{P}_{f t-1}\right)
$$

Ao assumir que $\left(\mathrm{P}_{v t}-\mathrm{P}_{v t-1}\right)=\Delta \mathrm{P}_{v}$ e $\left(\mathrm{P}_{f t}-\mathrm{P}_{f t-1}\right)=\Delta \mathrm{P}_{f t}$, a equação 2 torna-se:

$$
Y_{t}=q_{v} \Delta \mathrm{P}_{v}-q_{f} \Delta \mathrm{P}_{f}
$$

Quando se tem a efetividade perfeita de um hedge, tem-se: $\Delta \mathrm{P}_{v}-\Delta \mathrm{P}_{f}=0$. A variância da equação 3 é especificada como:

$$
\operatorname{Var}\left(Y_{t}\right)=\operatorname{Var}\left(q_{v} \Delta \mathrm{P}_{v}-q_{f} \Delta \mathrm{P}_{f}\right)
$$

Desenvolvendo a equação anterior, pressupondo $\Delta \mathrm{P}_{v} \quad e \quad \Delta \mathrm{P}_{f}$ correlacionados, se obtém:

$$
\sigma_{y}^{2}=q_{v}^{2} \sigma_{y}^{2}+q_{f}^{2} \sigma_{f}^{2}-2 q_{\nu} q_{f} \operatorname{cov}\left(\Delta \mathrm{P}_{v}, \Delta \mathrm{P}_{f}\right)
$$

em que $\sigma_{y}^{2}$ é a variância da receita do hedge; $\sigma_{y}^{2} e \sigma_{f}^{2}$ são as variâncias das mudanças de preços nos mercados físico e futuro, respectivamente; $\operatorname{cov}\left(\Delta \mathrm{P}_{v}, \Delta \mathrm{P}_{f}\right)$ é a covariância entre as mudanças do preço nos mercados físico e futuro.

Ao derivar a equação 5 , com relação a $q_{f}$ e igualar a zero, chega-se à condição de primeira ordem para a minimização da variância da receita do hedger, isto é:

$$
\frac{\partial \sigma_{y}^{2}}{\partial q_{f}}=2 \mathrm{q}_{f} \sigma_{f}^{2}-2 \mathrm{q}_{v} \operatorname{cov}\left(\Delta \mathrm{P}_{v t}, \Delta \mathrm{P}_{f t}\right)=0
$$

Para que se tenha na função um ponto de mínimo, a derivada segunda da equação 6 exige que $2 \sigma_{v}^{2}>0$. A equação 6 , após algumas simplificações, pode ser especificada como: 


$$
q_{f}=\frac{\mathrm{q}_{v} \operatorname{cov}\left(\Delta \mathrm{P}_{v}, \Delta \mathrm{P}_{f}\right)}{\sigma_{f}^{2}}
$$

Alternativamente, a equação 7 pode ser escrita como:

$$
h=\frac{\operatorname{cov}\left(\Delta \mathrm{P}_{v}, \Delta \mathrm{P}_{f}\right)}{\sigma_{f}^{2}}
$$

em que $h=\frac{q_{f}}{q_{v}}$

A equação 8 , ao atender às condições de primeira e segunda ordem da derivada, gera a razão $h$, que é conhecida na literatura especializada como razão ótima de hedge. Assim, $h$ revela o tamanho da posição assumida pelo investidor no mercado futuro, em relação à sua posição no mercado à vista. Mais especificamente, isso significa que a minimização da variância da receita obtida pelo hedge depende de forma direta da covariância entre as variações nos preços à vista e futuro, $\operatorname{cov}\left(\Delta \mathrm{P}_{i t}, \Delta \mathrm{P}_{j t}\right)$, e inversamente da variância do preço futuro $\sigma_{f}^{2}$.

Com a razão $h$ formalizada, pode-se deduzir a efetividade do hedge. ${ }^{6}$ Tecnicamente, essa razão resulta da substituição da equação 7 na equação 5, que, após algumas simplificações algébricas, é escrita como:

$$
\sigma_{y}^{2}=q_{v}^{2}\left(\sigma_{v}^{2}-\frac{\left[\operatorname{cov}\left(\Delta P_{v}, \Delta P_{f}\right)\right]^{2}}{\sigma_{f}^{2}}\right)
$$

De forma equivalente, a equação 9 também pode ser reespecificada como:

$$
\sigma_{y}^{2}=q_{v}^{2}\left(\sigma_{v}^{2}-\frac{\left[\operatorname{cov}\left(\Delta P_{v}, \Delta P_{f}\right)\right]^{2}}{\sigma_{f}^{2}}\right) \cdot\left(\frac{\sigma_{v}^{2}}{\sigma_{v}^{2}}\right)
$$

Ou, ainda, como:

$$
\sigma_{y}^{2}=q_{v}^{2} \sigma_{v}^{2}\left(1-\left[\frac{\operatorname{cov}\left(\Delta P_{v}, \Delta P_{f}\right)}{\sigma_{v} \sigma_{f}}\right]^{2}\right)
$$

Proporção da variância da receita obtida pelo hedger que pode ser eliminada através da constituição de um portfólio com a razão ótima de hedge.

FREITAS, C. A.; ALVES, W. B. Análise da Efetividade e da Razão Ótima do Hedge do Boi... 
Como o coeficiente de correlação linear entre as mudanças dos preços nos mercados e futuros $(\rho)$ é dado por:

$$
\rho=\frac{\operatorname{cov}\left(\Delta P_{v}, \Delta P_{f}\right)}{\sigma_{v} \sigma_{f}}
$$

Ao substituir a equação 12 na equação 11 , obtém-se:

$$
\sigma_{y}^{2}=q_{v}^{2} \sigma_{v}^{2}\left(1-\rho^{2}\right)
$$

No entanto, para Johnson (1960), a efetividade do hedge é a proporção da variância da receita do hedge, no presente caso representado por $\left(\sigma_{y}^{2}\right)$, eliminado através da composição de um portfólio com razão ótima de hedge. Essa razão é representada, matematicamente, como:

$$
e=\left(1-\frac{\sigma_{y}^{2}}{q_{v}^{2} \sigma_{v}^{2}}\right)
$$

em que e é a razão ótima do hedge; $q_{v}^{2} \sigma_{v}^{2}$ é a variância da receita de um portfólio sem hedge.

Ao substituir a equação 14 na equação 13 e proceder a algumas simplificações, resulta em:

$$
e=\rho^{2}
$$

A identidade retratada pela equação 15 evidencia que a efetividade de hedge é resultante do quadrado da correlação linear entre os preços à vista e futuro.

As estimações da razão ótima de hedge e de cross-hedge são feitas a partir da teoria do portfólio apresentada anteriormente, visto que a razão ótima nada mais é do que o percentual do ativo físico a ser protegido pelo agente para maximizar o retorno minimizar o risco. No entanto, há vários modos de se estimar a efetividade do hedge, bem como sua razão ótima. Nos parágrafos seguintes são apresentados resumidamente o desenvolvimento histórico dos principais modelos utilizados para tal finalidade, bem como os propósitos dos mesmos e suas limitações.

Stein (19617 apud EDERINGTON, 1979) usou pela primeira vez a teoria do portfólio em seu estudo para explicar os motivos pelos quais os agentes manti7 STEIN, J. L. The simultaneous determination of spot and futures prices. The American Economic
Review, v. 51, n. 5, p. 1012-1025, 1961. 
nham somente parte de seus ativos protegidos. Essa concepção contrariava a teoria clássica, até então preponderante, que só admitia um hedge completo, ou seja, todo o estoque físico deveria ser coberto no mercado futuro.

Ederington (1979) demonstrou de que maneira a razão de hedge e a efetividade do mesmo poderiam ser derivadas da teoria do portfólio. A efetividade do hedge foi medida comparando o risco de uma carteira sem uso de hedge com outra que continha tanto ativo com hedge quanto ativo sem hedge. O autor estimou, através do método dos Mínimos Quadrados Ordinários (MQO), uma regressão de preços à vista sobre os preços futuros, ambos em nível. O problema nesse método de estimação é o fenômeno da regressão espúria. Apesar da limitação metodológica desse estudo, o autor conclui que a teoria do portfólio explica de maneira mais eficiente a utilização de operações de hedge do que as teorias precedentes.

Para tentar corrigir esses problemas, Brown (1985' apud MYERS; THOMPSON, 1989) estimou uma regressão através do método de MQO com dados dos retornos do mercado à vista sobre os retornos do mercado futuro, sendo, nesse caso, retorno definido como a mudança proporcional nos preços em um dado espaço de tempo. $\mathrm{O}$ autor chegou à conclusão de que nenhum dos métodos testados regressões em nível, em diferença e variações dos retornos - são apropriados para estimar a razão ótima do hedge, exceto em circunstâncias especiais.

Para superar essa dificuldade, esse autor desenvolveu um método de abordagem para estimar a razão ótima de hedge. O método consiste em estimar uma regressão múltipla, por $\mathrm{MQO}$, e interpretar o coeficiente $\delta$ como a razão ótima de hedge.

$$
P_{v t}=\delta P_{f t}+X_{t-1} \alpha+\varepsilon_{t}
$$

em que $X_{t-1}$ é uma matriz que contém todas as variáveis consideradas importantes para a formação dos preços à vista e futuro.

Segundo os autores, as principais variáveis que deveriam ser colocadas nessa matriz são $P_{v t}$ e $P_{f t}$ defasados; $\alpha$ é um vetor de coeficientes; $\delta$ é o coeficiente do preço futuro e $\varepsilon_{t}$ um termo de erro, conhecido em séries temporais como ruído branco.

Dessa forma, a equação 16 pode ser especificada como:

$$
P_{v t}=\alpha_{0}+\delta P_{f t}+\sum_{i=1}^{q} \alpha_{t} P_{v t-i}+\sum_{j=1}^{q} \alpha_{q+j} P_{f t-j}+\varepsilon_{t}
$$

em que $q$ é o número de defasagens do modelo; $P_{v t-1}$ e $P_{f t-1}$ são, respectivamente, os preços à vista e futuro defasados.

8 BROWN, S. L. A reformulation of portfolio model of hedging. American Journal of Agricultural Economics, v. 67, n. 3, p. 508-512, 1985.

FREITAS, C. A.; ALVES, W. B. Análise da Efetividade e da Razão Ótima do Hedge do Boi... 
A efetividade do hedge é obtida através do coeficiente de determinação da equação 17. No entanto, Silveira (2002) ressalta que essa forma de cálculo não está correta. A maneira apropriada de se estimar essa efetividade está apresentada na seção seguinte.

\section{Metodologia}

Como os dados do presente trabalho são séries temporais, faz-se necessário adotar alguns procedimentos econométricos, os quais estão sucintamente apresentados a seguir.

\subsection{Procedimentos Econométricos 9}

Como o presente estudo utiliza-se de processos estocásticos, são realizados os testes de estacionariedade através da Função de Autocorrelação (FAC) e dos testes de Dickey-Fuller (DF), Dickey-Fuller Aumentado (ADF) e Phillip-Perron (PP). ${ }^{10}$

A partir do diagnóstico da ordem de integração das séries, realiza-se o teste de cointegração, o qual tem por propósito avaliar se existe alguma relação de equilíbrio de longo prazo entre as séries temporais (não estacionárias e integradas de mesma ordem). Para realizar tal teste, utiliza-se a abordagem desenvolvida por Johansen. ${ }^{11}$

Testada a cointegração dos processos, inclui-se no modelo um vetor de correção de erro (VECM), o qual possibilita diagnosticar se o modelo está ou não em equilíbrio no curto prazo.

Finalmente, são utilizados os critérios de informação de Akaike (AIC) e de Schwarz (BIC) na definição do número de defasagens dos preços utilizado para estimação da regressão para obtenção da efetividade e razão ótima do hedge e do cross-hedge.

\subsection{O Risco de Base e o Modelo Econométrico}

O cálculo do risco de base é relevante para o desenvolvimento do presente estudo, pois, através do mesmo, pode-se analisar o risco de efetuar tanto o hedge do boi gordo quanto o cross-hedge do bezerro. A base é definida como sendo a diferença entre o preço físico da commodity numa determinada região e o seu preço futuro cotado em bolsa, sendo a mesma descrita como:

\footnotetext{
$9 \quad$ Os modelos econométricos são estimado pelo software Stata 10.1 licenciado no Departamento de Ciências Econômicas da Universidade Federal de Santa Maria.

10 Se o leitor desejar uma abordagem mais introdutória sobre o tema, ver Gujarati (2006, p. 654) ou Enders (2010) para uma análise mais aprofundada.

11 Ver Enders (2010, p. 385-401).
} 


$$
B=P B_{v t}-P_{f t}
$$

em que $B$ é a base; $P B_{v t}$ é o preço à vista na base da commodity em questão.

Caso o preço à vista seja maior que o preço futuro, a base assume um valor positivo, caso contrário, a base assumirá um valor negativo. Outra característica importante da base é que esta não é constante ao longo do tempo, pois tanto o preço à vista quanto o preço futuro variam de acordo com os movimentos do mercado.

Os cálculos da base do bezerro e do boi gordo são realizados, respectivamente, através das especificações a seguir:

$$
\begin{gathered}
B_{B e z}=\left(16,5 \cdot P_{v t}^{B o i}-16,5 \cdot P_{f t}^{B o i}\right)+\left(P_{v t}^{B e z}-16,5 \cdot P_{v t}^{B o i}\right) \\
B_{B o i}=16,5 \cdot P_{v t}^{B o i}-16,5 \cdot P_{f t}^{B o i}
\end{gathered}
$$

em que, $B_{B e z}$ é a base diária por unidade de bezerro na semana de vencimento do contrato futuro do boi gordo na BMËF-Bovespa; $P_{v t}^{B o i}$ é o preço à vista por unidade de boi na semana de vencimento do contrato futuro do boi gordo na BMEF-Bovespa; $P_{f t}^{B o i}$ é o preço futuro por unidade de boi na semana de vencimento do contrato futuro; e $P_{v t}^{B e z}$ é o preço à vista por unidade de bezerro na semana de vencimento do contrato futuro.

De posse das bases calculadas através das equações 19 e 20, e tendo como referência Fontes et al. (2005), calcula-se as bases médias gerais para todos os meses de vencimento do contrato futuro do boi gordo na BMEFF, seguindo a seguinte especificação:

$$
B_{\text {médiaG }}=\frac{1}{n} \sum_{n}^{1} B_{t}
$$

em que $B_{\text {médiaG }}$ representa os valores das bases médias gerais, $B_{t}$ representa os valores da base no mês $t$ e $n$ é o número de bases utilizadas.

Com os resultados obtidos para as bases médias gerais, calcula-se o risco de base para todos os meses de vencimento do contrato referido anteriormente, através da equação proposta pelo autor supracitado, formalizada como:

$$
S_{B A S E}=\sqrt{\frac{1}{n-1} \sum\left(B_{t}-B_{t-1}\right)^{2}}
$$

em que, $\mathrm{RB}$ representa o risco de base. 
Para tornar possível quantificar a diferença entre o risco de base do hedge e do cross-hedge, estima-se um modelo de regressão por MQO com segue:

$$
\operatorname{In}\left(S_{B A S E}\right)=\vartheta_{1}+\vartheta_{2} \text { Tipo }_{i}+z_{t}
$$

em que, $\ln \left(S_{B A S E}\right)$ é o logaritmo neperiano do desvio padrão da base na semana de vencimento do contrato; $T_{i p o_{i}}$ é a variável binária que representa o produto em questão, sendo zero quando se referir ao bezerro e 1 (um) quando se referir ao boi gordo; $z_{t}$ é o termo de erro; $\vartheta_{1}$ é o intercepto da função; e $\vartheta_{2}$ é o coeficiente da variável binária.

Para obter o efeito da variável binária, referente ao tipo de animal sobre o risco da base, define-se a equação 24 , a qual permite quantificar, percentualmente, a diferença entre o risco de base do boi gordo e do bezerro $(\Delta R)$.

$$
\Delta R=\left(\exp \left(\vartheta_{2}\right)-1\right) \cdot 100
$$

O modelo econométrico utilizado, no presente estudo, para estimar a razão ótima de hedge e de cross-hedge, está em consonância com Myers e Thompson (1989). A especificação desse modelo é dada pela equação 17, em primeira diferença. Formalmente:

$$
\Delta P_{v t}=h \Delta P_{f t}+\sum_{i=1}^{q} \beta_{i} \Delta P_{v t-i}+\sum_{j=1}^{q} \alpha_{q+j} \Delta P_{f t-j}+u_{t}
$$

em que $\Delta(\cdot)$ representa $P_{v t}, P_{f t}, P_{v t-i}$ e $P_{f t-j}$ em primeira diferença, respectivamente; $u_{t}$ é o vetor de erro e os coeficientes; e, $\beta$ e $\alpha$ são os parâmetros a serem estimados.

Na equação 25, o valor de $h$ representa a razão ótima de hedge (cross-hedge), sendo estatisticamente equivalente ao valor gerado pela equação 8 .

Realizado o cálculo da razão ótima de hedge e de cross-hedge, passa-se a verificar a existência de diferença no percentual do estoque físico necessário para manter sobre proteção, com o intuito de minimizar os riscos de preço, quando se leva em consideração os períodos de safra e entressafra. Para isso, uma variável dummy $\left(D_{i}\right)$ é adicionada à equação 25 , obtendo-se:

$$
\Delta P_{v t}=h \Delta P_{f t}+\sum_{i=1}^{q} \beta_{i} \Delta P_{v t-i}+\sum_{j=1}^{q} \alpha_{q+j} \Delta P_{f t-j}+\lambda D_{i} \Delta P_{f t}+u_{t}
$$

em que $D_{i}$ assume valor 1 (um) se o período é de safra e 0 (zero) caso contrário. Define-se como o período de safra para o boi gordo o primeiro semestre, logo o segundo semestre é considerado de entressafra. Já para o bezerro, os meses de abril 
a julho são considerados de safra, sendo os demais meses do ano considerados de entressafra.

Estimado o coeficiente $h$ na equação 25 ou na equação 26, calcula-se a efetividade através da equação 27, adaptada da equação 14.

$$
e=\left(1-\frac{\operatorname{Var}(h)}{\operatorname{Var}(p)}\right)
$$

em que e é a efetividade do hedge, Var(h) é a variância de um portfólio com hedge na proporção ótima e $\operatorname{Var}(p)$ é a variância da receita de um portfólio sem hedge.

A efetividade do hedge varia entre zero e um, sendo considerada sem efetividade quando e for igual a zero, ou seja, não houver correlação entre os preços, e com efetividade máxima quando e for igual a um, o que neste caso as mudanças de preços serão perfeitamente correlacionadas.

Para se chegar ao valor dessa efetividade, deve-se primeiramente calcular, para uma posição sem hedge, a diferença de preços $(t-t-1)$. $O$ mesmo procedimento é adotado para uma posição com hedge. Isso é feito da seguinte forma: à série diferenciada da posição sem hedge é adicionada uma série diferenciada de preços futuros, sendo esta multiplicada pela razão ótima de hedge (cross-hedge), obtida no procedimento realizado anteriormente. Essa mecânica está exemplificada no Quadro 1. Após a realização desses cálculos, são calculadas as variâncias para ambos os portfólios para, então, obter a efetividade, através da equação $27 .{ }^{12}$

Quadro 1 - Exemplo do cálculo da efetividade do hedge

\begin{tabular}{|c|c|c|c|}
\hline \multicolumn{2}{|c|}{ Portfólio 1 (sem hedge) } & \multicolumn{2}{|c|}{ Portfólio 2 (com hedge) } \\
\hline $\begin{array}{c}\text { Preço à vista }\left(P_{v t}\right) \\
\text { em } R \$\end{array}$ & $\begin{array}{c}\text { Série diferenciada } \\
\text { Preço à vista } R \$ \text { : } \\
\left(P_{v t}-P_{v t-1}\right)\end{array}$ & $\begin{array}{c}\text { Preço futuro }\left(P_{f t}\right) \\
\text { em R\$ }\end{array}$ & $\begin{array}{l}\text { Série diferenciada } \\
\text { em } R \$ \text { : } \\
\left(P_{v t}-P_{v t-1}\right)-q_{v^{*}}\left(P_{f_{t}}-P_{f t-1}\right)\end{array}$ \\
\hline$P_{v 1}=697$ & $697-697=0$ & $P_{f 1}=687$ & $\begin{array}{c}(697-697)- \\
0,45(687-687)=0\end{array}$ \\
\hline$P_{v 2}=705$ & $705-697=8$ & $P_{f 2}=695$ & $\begin{array}{c}(705-697)-0,45(695 \\
-687)=4,40\end{array}$ \\
\hline$P_{v 3}=694$ & $694-697=-3$ & $P_{f 3}=692$ & $\begin{array}{c}(694-697)-0,45(692 \\
-687)=-5,25\end{array}$ \\
\hline
\end{tabular}

Fonte: Elaboração própria.

\section{As Fontes e a Base de Dados}

A série de preços utilizada é composta por uma média dos preços nos principais pontos de abate bovino no estado de São Paulo, a saber, nas regiões de Presi-

$\overline{12}$ O valor de $q_{v}=0,45$ utilizado no exemplo do portfólio 2 (com hedge) é meramente ilustrativo. 
dente Prudente, Araçatuba, Bauru e São José do Rio Preto. ${ }^{13}$ Nessas regiões, são colhidas as informações pelo Centro de Estudos Avançados em Economia Aplicada da Escola Superior Luiz de Queiroz (Cepea/Esalq) ${ }^{14}$ para compor o indicador desenvolvido.

Os preços à vista e futuro do boi gordo serão multiplicados por 16,5, a fim de se obter tais preços em reais por cabeça de animal, já que essas séries estão mensuradas em reais por arroba. A multiplicação por esse número se deve ao fato de que o peso padrão de um boi gordo com idade superior a 36 meses é de 16,5 arrobas. Assim, é possível obter a base por unidade de animal. Os preços do bezerro já se encontram em reais por cabeça.

O período analisado foi de abril de 2001 a março de 2010. O início em abril de 2001 se deve à modificação ocorrida na especificação do contrato futuro do boi gordo em março desse ano, ${ }^{15}$ conforme já sinalizado anteriormente. Todas as séries referidas possuem cotações diárias, porém são utilizadas médias semanais para o cálculo do risco de base, para a razão ótima e efetividade, tanto do hedge quanto do cross-hedge.

Cabe ressaltar que os preços se referem, respectivamente, ao bovino macho, castrado, comum e rastreado, com 16 arrobas ou mais, e ao bezerro desmamado, macho, da raça nelore e com idade entre oito e doze meses. Os preços dos contratos futuros do boi gordo foram obtidos na BMEF-Bovespa e correspondem ao primeiro vencimento desse contrato.

\section{Resultados e Discussões}

\subsection{Os Testes Econométricos}

A identificação dos processos autorregressivos presentes nas séries estudadas é um dos primeiros procedimentos requisitados nas estimativas de séries temporais. Na Tabela 1, estão apresentadas as ordens dos processos autorregressivos de todas as séries de preços semanais utilizadas no estudo. Como há divergência entre os critérios de informação de Akaike e de Schwarz, opta-se pela utilização da menor defasagem indicada por um dos critérios.

\footnotetext{
$13 \quad$ O peso de cada região na composição do indicador é definido com base nos dados de volume de abate dos frigoríficos amostrados - atualizado mensalmente. A participação de cada região é definida pela soma dos volumes de abate das unidades que possuem cadastro no Serviço de Inspeção Federal (SIF), consideradas no levantamento do dia.

14 Disponível em: <http://cepea.esalq.usp.br/boi/> . Acesso em: 22 jan. 2010.

15 Até então, o contrato futuro do boi gordo era cotado em pontos por arroba líquida, sendo cada ponto correspondente à taxa de câmbio de reais por dólar.
} 
Tabela 1 - Ordem dos processos autorregressivos indicadas pelo AIC e SBC

\begin{tabular}{cccccc}
\hline \multicolumn{2}{c}{ Preço à vista do boi gordo } & \multicolumn{2}{c}{ Preço futuro do boi gordo } & \multicolumn{2}{c}{ Preço à vista do bezerro } \\
\hline AIC & SBC & AIC & SBC & AIC & SBC \\
$\mathrm{AR}(12)$ & $\mathrm{AR}(5)$ & $\mathrm{AR}(2)$ & $\mathrm{AR}(1)$ & $\mathrm{AR}(7)$ & $\mathrm{AR}(4)$ \\
\hline
\end{tabular}

Fonte: Elaborada própria.

Após a obtenção da ordem do processo autorregressivo, testa-se a existência ou não de raiz unitária na série em nível e, em caso afirmativo, procede-se ao mesmo teste para as séries em diferenças e, assim, sucessivamente, até que nestas não existam mais raiz unitária. Para tanto, são utilizados os testes da função de autocorrelação (FAC), Dickey-Fuller Aumentado (ADF) e Phillip-Perron (PP).

Os resultados desses testes para as séries em níveis e em primeira diferença encontram-se na Tabela $2 .{ }^{16}$ Percebe-se que todas as séries possuem raiz unitária, pois as estatísticas calculadas de ADF e PP são menores, em módulo, que as estatísticas críticas de $\mathrm{ADF}(-3,4215)$. O próximo passo é testar se há raiz unitária nas séries em primeira diferença. Conforme se pode notar nessa tabela, as estatísticas calculadas dos testes de DF, ADF e PP para todas as séries em primeira diferença são maiores em módulo do que a estatística crítica a 5\% de significância. Isso significa que tais séries não possuem raiz unitária em sua primeira diferença.

Tabela 2 - Teste de estacionariedade para as séries de preços semanais

\begin{tabular}{cccc}
\hline \multirow{4}{*}{ Teste } & \multicolumn{3}{c}{ Séries em nível } \\
\hline & $\begin{array}{c}\text { Preço à vista do boi } \\
\text { gordo }\end{array}$ & $\begin{array}{c}\text { Preço futuro do boi } \\
\text { gordo }\end{array}$ & $\begin{array}{c}\text { Preço à vista do } \\
\text { bezerro }\end{array}$ \\
\cline { 2 - 4 } & Estatística $-\mathrm{t}$ & Estatística $-\mathrm{t}$ & Estatística $-\mathrm{t}$ \\
\hline $\mathrm{ADF}^{*}$ & $-2,0713$ & $-2,2467$ & $-1,9756$ \\
$\mathrm{PP}$ & $-0,74782$ & $-0,99390$ & 1,1234 \\
\hline & Séries em primeira diferença & \\
\hline Teste & Preço à vista do boi & Preço futuro do boi & Preço à vista do \\
& gordo & gordo & bezerro \\
\cline { 2 - 4 } & Estatística $-\mathrm{t}$ & Estatística $-\mathrm{t}$ & Estatística $-\mathrm{t}$ \\
\hline $\mathrm{DF} *$ & $-11,7422$ & $-16,8228$ & $-11,7341$ \\
$\mathrm{ADF}$ & $-10,4597$ & $-14,9188$ & $-4,9513$ \\
$\mathrm{PP}$ & $-11,9276$ & $-17,0456$ & $-12,1913$ \\
\hline
\end{tabular}

Fonte: Elaboração própria.

Nota: *valor crítico do teste de Dickey-Fuller ao nível de significância de 5\% = -3,4215; **valor crítico do teste ao nível de significância de $5 \%=-2,8681$.

Esses valores foram obtidos considerando-se as defasagens obtidas através da identificação do processo autorregressivo, quais sejam $\mathrm{p}=5, \mathrm{p}=1$ e $\mathrm{p}=4$, respectivamente, para o preço à vista do boi gordo, preço futuro do boi gordo e preço à vista do bezerro.

FREITAS, C. A.; ALVES, W. B. Análise da Efetividade e da Razão Ótima do Hedge do Boi... 
Ao realizar o teste da FAC, também se obtêm os mesmos resultados dos testes anteriores. Os correlogramas não foram incorporados ao texto por motivo de delimitação de páginas. Para a série em nível, percebe-se a existência de um padrão típico de séries não estacionárias, pois se percebe que todas as variáveis possuem um componente de memória muito forte, ou seja, as séries sofrem grande influência de seus valores passados. Já quando se analisa as séries em primeira diferença, percebe-se que não há um padrão para os valores durante o tempo, ou seja, estes variam de forma aleatória em torno de um valor médio. Além disso, a memória cai rapidamente durante as primeiras defasagens. Assim, têm-se indícios estatísticos de que os preços presentes não sofrem grande influência dos preços passados mais defasados, mostrando padrão de processos estacionários. ${ }^{17}$

O próximo passo a ser realizado é testar se há cointegração entre as variáveis preço à vista e preço futuro do boi gordo e entre o preço à vista do bezerro e preço futuro do boi gordo. Como destacado anteriormente, o pré-requisito para a realização do teste de cointegração está satisfeito, isto é, as séries de preços são integradas de mesma ordem I(1).

Para realizar o teste de cointegração, é preciso definir, primeiramente, o número de defasagens do vetor autorregressivo a ser utilizado. Isso é feito através dos critérios de AIC e SBC. Em caso dos critérios divergirem quanto à extensão da defasagem, utiliza-se o critério de menor defasagem, primando sempre por especificações mais parcimoniosas. Os resultados encontram-se na Tabela 3. As estatísticas selecionadas estão destacadas em negrito.

Tabela 3 - Critérios de informação de Akaike e Schwarz para o boi gordo e o bezerro

\begin{tabular}{ccccc}
\hline \multirow{2}{*}{$N^{\circ}$ de defasagens } & \multicolumn{2}{c}{ Preço à vista do boi gordo } & \multicolumn{2}{c}{ Preço à vista do bezerro } \\
\cline { 2 - 5 } & AIC & SBC & AIC & SBC \\
\hline 0 & $-5598,1$ & $-5598,1$ & $-6071,9$ & $-6071,9$ \\
1 & $-3634,4$ & $-3642,6$ & $-3329,0$ & $-3337,2$ \\
2 & $-3562,3$ & $-3578,7$ & $-3242,2$ & $-3258,6$ \\
3 & $-3535,5$ & $-3560,1$ & $-3225,7$ & $-3250,3$ \\
4 & $-3524,7$ & $-3557,5$ & $-3221,2$ & $-3254,0$ \\
5 & $-3525,2$ & $-3566,2$ & $-3215,4$ & $-3256,4$ \\
6 & $-3523,5$ & $-3572,7$ & $-3216,5$ & $-3265,7$ \\
7 & $-3526,2$ & $-3583,6$ & $-3217,3$ & $-3274,7$ \\
8 & $-3524,3$ & $-3590,0$ & $-3214,2$ & $-3279,8$ \\
9 & $-3525,0$ & $-3598,8$ & $-3213,7$ & $-3287,5$ \\
10 & $-3528,0$ & $-3610,0$ & $-3213,8$ & $-3295,8$ \\
\hline
\end{tabular}

Fonte: Elaboração própria.

17 Os gráficos referentes à FAC, tanto para as séries em nível, quanto para as séries em primeira diferença, foram suprimidos do corpo do trabalho a fim de se adequar o artigo às normas da Revista Análise Econômica, em relação ao número de páginas. 
As defasagens obtidas para as séries estudadas foram maiores para o AIC vis-à-vis o SBC nos dois casos. Dessa forma, as defasagens a serem utilizadas serão quatro para o preço à vista do boi gordo e três para o preço à vista do bezerro, conforme o critério SBC. Definidas as defasagens, realizam-se os testes de cointegração de Johansen, do traço e do máximo autovalor para as duas séries de preços à vista, do boi gordo e do bezerro.

Conforme a Tabela 4, é possível, com base no teste do máximo autovalor para as séries de preços do boi gordo à vista e futuro, rejeitar a hipótese nula do rank igual a 0 , na medida em que o valor calculado $(35,6315)$ é superior ao valor tabelado $(15,8700)$, ao nível de significância de $5 \%$. Por outro lado, não se rejeita a hipótese nula de apenas um vetor de cointegração através desse teste, já que a estatística calculada é inferior à tabelada. Essa mesma conclusão é obtida, também, pelo teste do traço, pois, com 95\% de confiança, é possível rejeitar a hipótese nula de rank igual a 0, pelo fato da estatística calculada $(38,4249)$ ser superior à estatística crítica $(20,1800)$. Contudo, essa hipótese não pode ser rejeitada para um vetor de cointegração ao nível de confiança de $95 \%$, pois a estatística calculada do teste do traço $(2,7934)$ é menor do que a tabelada $(9,1600)$. Esses dois testes apontam para uma relação a longo prazo entre o preço à vista do boi gordo e o preço futuro dessa commodity.

Tabela 4 - Teste de cointegração baseado no teste do traço do máximo autovalor

\begin{tabular}{cccccc}
\hline \multicolumn{4}{c}{ Preço à vista do boi bordo versus preço futuro do boi gordo } \\
\hline $\begin{array}{c}\text { Hipótese nula } \\
\text { testada }\end{array}$ & $\begin{array}{c}\text { Hipótese } \\
\text { alternativa } \\
\text { testada }\end{array}$ & Estatística calculada & \multicolumn{2}{c}{$\begin{array}{c}\text { Estatística crítica } \\
(\alpha=5 \%)\end{array}$} \\
\hline $\mathrm{H}_{0}: \mathrm{r}$ & $\mathrm{H}_{1}: \mathrm{r}$ & $\lambda_{\max }$ & $\lambda_{\text {traco }}$ & $\lambda_{\max }$ & $\lambda_{\text {traco }}$ \\
\hline 0 & 1 & 35,6315 & 38,4249 & 15,8700 & 20,1800 \\
1 & 2 & 2,7934 & 2,7934 & 9,1600 & 9,1600 \\
\hline & Preço à vista do bezerro versus preço futuro do boi gordo & \\
\hline $\mathrm{H}_{0}: \mathrm{r}$ & $\mathrm{H}_{1}: \mathrm{r}$ & $\lambda_{\max }$ & $\lambda_{\text {traso }}$ & $\lambda_{\max }$ & $\lambda_{\text {traco }}$ \\
\hline 0 & 1 & 8,3242 & 10,4258 & 15,8700 & 20,1800 \\
1 & 2 & 2,1016 & 2,1016 & 9,1600 & 9,1600 \\
\hline
\end{tabular}

Fonte: Elaboração própria.

Quando se testam os vetores de preços à vista do bezerro e futuro do boi gordo, o resultado é diferente, pois os dois testes de cointegração realizados, traço e autovalor máximo, sugerem a não existência de vetor de cointegração, já que as estatísticas calculadas em ambos os testes são menores do que os seus valores críticos a 95\%. Isso significa que as duas séries não têm relação estatisticamente significativa a longo prazo. Uma explicação plausível para esse resultado é que se 
trata de dois ativos diferentes, então é compreensível, já que os preços desses dois ativos não variam necessariamente na mesma direção e magnitude. Isso já pode ser o primeiro indício de que o cross-hedge entre esses dois produtos não é muito eficiente.

O próximo passo consiste em mensurar a influência a longo prazo do preço à vista sobre o preço futuro do boi gordo, uma vez que essa relação é cointegrável. Os resultados estão na Tabela 5.

Tabela 5 - Resultado da relação a longo prazo entre o preço à vista e o preço futuro do boi gordo

\begin{tabular}{ccc}
\hline Variáveis & Estimativa dos parâmetros & Valores de $t$ \\
\hline Constante & 7,7096 & 0,1217 \\
Preço à vista do boi gordo & 1,0000 & - \\
Preço futuro do boi gordo & 1,0086 & 125,9652 \\
\hline
\end{tabular}

Fonte: Elaboração própria.

Conforme se pode notar, os sinais dos coeficientes estimados estão em consonância com a teoria econômica, dado que se espera uma relação positiva entre os preços presente e futuro. O coeficiente de inclinação é estatisticamente significativo a 1\%, sendo assim, o preço à vista do boi gordo influencia o preço futuro do boi gordo. Devido à magnitude desse coeficiente $(1,0086)$, pode-se dizer que toda variação no preço à vista é transmitida na mesma intensidade ao preço futuro do boi gordo.

Tendo chegado a esse resultado, estima-se o mecanismo de correção de erros (MCE) com o intuito de verificar qual o percentual da discrepância, entre as séries de preços, é corrigido durante as duas últimas semanas das séries em questão. Os resultados estão na Tabela 6.

Tabela 6 - Mecanismo de correção de erros (MCE) para o preço à vista do boi gordo

\begin{tabular}{ccc}
\hline Variáveis & Estimativa dos parâmetros & Valores de $t$ [p] \\
\hline Preço à vista em $1^{\text {a }}$ diferença & 0,46138 & $5,9641[.000]$ \\
Preço futuro em $1^{\text {a }}$ diferença & 0,20201 & $3,3030[.001]$ \\
Preço à vista em $2^{\text {a }}$ diferença & $-0,27885$ & $-3,7973[.000]$ \\
Preço futuro em $2^{\text {a }}$ diferença & $-0,031834$ & $-0,57175[.568]$ \\
Preço à vista em $3^{\text {a diferença }}$ & 0,084941 & $1,5790[.115]$ \\
Preço futuro em $3^{\text {a }}$ diferença & $-0,014063$ & $-0,28329[.777]$ \\
MCE & $-0,17283$ & $-3,0819[.002]$ \\
\hline
\end{tabular}

Fonte: Elaboração própria. 
Nota-se, Tabela 6, que o sinal do termo do erro defasado é negativo e menor do que 1 em módulo, estando coerente com o que se espera para uma série não explosiva e estatisticamente significativa em até $99 \%$ de confiança. Assim, os resultados estimados permitem afirmar que cerca de 17\% das discrepâncias dos preços efetivos e esperados a longo prazo do contrato futuro de boi gordo da BMEFF-Bovespa são corrigidas nas duas últimas semana, o que torna a série convergente.

\subsection{O Risco de Base}

A análise do risco de base tem como finalidade verificar se as mecânicas do hedge e o cross-hedge são eficientes na proteção dos agentes aos riscos de variações de preços. Quanto maior o risco de base, menor é a viabilidade de utilização dessas ferramentas no gerenciamento dos riscos dos produtores, uma vez que o fortalecimento da base é bom para quem está na posição vendido, ou favorável aos produtores e, ruim, para quem está na posição comprado, no caso o agente que comprou no mercado futuro.

Conforme apontado na seção 3.3, o período de safra do boi gordo corresponde ao primeiro semestre de cada ano e a safra do bezerro vai de abril a julho. Pela Tabela 7, é possível visualizar que o risco de base do boi gordo não é sistematicamente maior nos períodos de safra. Esse resultado está em consonância com Oliveira Neto e Figueiredo (2009), pois, segundo os autores, cada vez mais os avanços técnicos no confinamento dos animais e na pastagem promovem melhor distribuição da oferta da produção ao longo do ano, tornando menos visível a variação do risco de base entre safra e entressafra.

Os resultados evidenciam que, ao contrário do boi gordo, para o bezerro (Tabela 8) o risco de base é relativamente maior no período de safra. Isso revela que os preços tendem a ser mais previsíveis e seu risco mais fácil de ser controlado quando aumenta a oferta de bezerro.

No entanto, conforme afirma Bigma Consultoria,$^{18}$ tanto o preço do bezerro quanto o do boi gordo vêm experimentando forte tendência de alta nos preços desde 2006. Segundo essa consultoria, de 2006 até julho de 2011, o preço do bezerro subiu $126 \%$ e o do boi $112 \%$. Assim, o período de análise do presente estudo foi muito favorável para essas duas atividades, demonstrando, especialmente para o caso do bezerro, perda de eficiência das operações de cross-hedge.

$\overline{18}$ Disponível em: <http://www.bigma.com.br/artigos.asp?id=177>. Acesso em: 28 nov. 2012.

FREITAS, C. A.; ALVES, W. B. Análise da Efetividade e da Razão Ótima do Hedge do Boi... 
Tabela 7 - Valores máximo, mínimo, base média geral e risco de base para o boi gordo (em R\$) entre os meses de abril de 2001 e março de 2010

\begin{tabular}{cccccc}
\hline Mês & Valor mínimo & Valor máximo & $\begin{array}{c}\text { Base média } \\
\text { geral }\end{array}$ & Risco de base & $\begin{array}{c}\text { Log (Risco de } \\
\text { base) }\end{array}$ \\
\hline Jan. & $-2,72$ & 6,04 & 1,43 & 2,65 & 0,97 \\
Fev. & $-4,18$ & 1,98 & $-0,10$ & 2,04 & 0,71 \\
Mar. & $-7,52$ & 3,17 & $-0,10$ & 2,98 & 1,09 \\
Abr. & $-4,52$ & 1,02 & $-1,06$ & 1,87 & 0,63 \\
Maio & 0,07 & 8,13 & 1,68 & 2,52 & 0,92 \\
Jun. & $-1,72$ & 14,69 & 3,38 & 5,34 & 1,68 \\
Jul. & $-3,23$ & 8,75 & 2,52 & 3,82 & 1,34 \\
Ago. & $-9,04$ & 0,69 & $-2,71$ & 3,38 & 1,22 \\
Set. & $-1,16$ & 5,18 & 1,91 & 2,17 & 0,77 \\
Out. & $-4,52$ & 9,90 & 0,59 & 4,46 & 1,50 \\
Nov. & $-6,83$ & 2,48 & $-0,47$ & 3,30 & 1,19 \\
Dez. & $-0,04$ & 33,60 & 5,98 & 10,55 & 2,36 \\
\hline
\end{tabular}

Fonte: Elaboração própria.

Tabela 8 - Valores máximo e mínimo, base média geral e risco de base para o bezerro (em R\$) entre os meses de abril de 2001 e março de 2010.

\begin{tabular}{cccccc}
\hline Mês & Valor mínimo & Valor máximo & $\begin{array}{c}\text { Base média } \\
\text { geral }\end{array}$ & Risco de base & $\begin{array}{c}\text { Log (Risco de } \\
\text { base) }\end{array}$ \\
\hline Jan. & $-742,76$ & $-372,32$ & $-580,23$ & 121,66 & 4,80 \\
Fev. & $-734,98$ & $-372,82$ & $-578,89$ & 111,83 & 4,72 \\
Mar. & $-736,46$ & $-344,20$ & $-559,89$ & 116,83 & 4,76 \\
Abr. & $-702,11$ & $-306,82$ & $-509,76$ & 126,49 & 4,84 \\
Maio & $-712,55$ & $-339,97$ & $-510,18$ & 132,73 & 4,89 \\
Jun. & $-794,55$ & $-338,24$ & $-529,93$ & 150,85 & 5,02 \\
Jul. & $-770,99$ & $-351,55$ & $-550,89$ & 136,06 & 4,91 \\
Ago. & $-779,85$ & $-352,48$ & $-569,13$ & 125,71 & 4,83 \\
Set. & $-759,93$ & $-383,96$ & $-574,31$ & 118,27 & 4,77 \\
Out. & $-752,19$ & $-419,16$ & $-593,64$ & 92,04 & 4,52 \\
Nov. & $-784,15$ & $-400,64$ & $-603,50$ & 121,10 & 4,80 \\
Dez. & $-710,17$ & $-394,35$ & $-587,71$ & 102,35 & 4,63 \\
\hline
\end{tabular}

Fonte: Elaboração própria.

As bases médias gerais e o risco de base associado às operações de hedge do boi gordo e de cross-hedge do bezerro são apresentadas nas Tabelas 7 e 8, respec- 
tivamente. Nestas estão contidos, também, os valores máximos e mínimos para a base em cada mês, representando a diferença máxima e mínima entre os preços à vista e futuro por animal. Conforme se pode perceber, os valores em reais são muito mais elevados para o bezerro vis-à-vis o boi gordo, mostrando que a diferença entre os preços à vista e o futuro do bezerro é muito maior do que o do boi gordo.

A partir das informações das duas tabelas anteriores, obteve-se uma base média geral para o bezerro situada entre - $R \$ 509,76$ e - $R \$ 603,50$, sendo esses valores muito superiores ao do boi gordo, o qual variou entre - $R \$ 2,71$ e $R \$ 5,98$. Isso significa que o preço à vista do bezerro se encontra, em média, entre $\mathrm{R} \$ 509,76 \mathrm{e}$ $\mathrm{R} \$ 603,50$, abaixo do preço futuro do boi gordo, enquanto que o preço à vista do boi gordo se encontra entre $R \$ 2,71$ mais baixo e $R \$ 5,98$ mais alto que o preço futuro do boi gordo, mostrando que as variações entre os preços do boi gordo e do bezerro são maiores do que se comparados os preços futuro e à vista do boi gordo.

Para verificar qual ativo gera maiores riscos de preços ao produtor, calcula-se o risco de base para ambos. A diferença de preços entre esses dois ativos é elevada, mas com maior risco para o bezerro de $\mathrm{R} \$ 150,85$. Para o boi gordo, essa diferença é de apenas $R \$ 10,55$, mostrando que o cross-hedger (bezerro versus boi gordo) possui um risco em suas operações muito mais elevado do que o hedge (boi gordo à vista versus boi gordo futuro). Com o intuito de quantificar essa diferença do risco de base entre o boi gordo e o bezerro, realiza-se a estimação da equação 24, a partir dos dados das Tabelas 8 e 9 referentes ao campo log do risco de base.

A Tabela 9 mostra os resultados obtidos através da estimação da equação de regressão supracitada. A partir das estatísticas $\mathrm{F}$ e $t$, é possível perceber que a regressão se mostrou significativa, em termos estatísticos, a 1\%, e o modelo utilizado explicou uma grande parte do risco de base, visto que o valor dos coeficientes de determinação ficou próximo a 0,9650. A variável binária tipo de animal explica, aproximadamente, $96,50 \%$ da variação do risco de base entre o boi gordo e o bezerro.

A estimativa da equação 25 revela que a diferença no risco de base entre o boi gordo e o bezerro é de $97,25 \%$, ou seja, o risco de base do boi gordo é muito menor do que o do bezerro.

Tabela 9 - Resultado da regressão do logaritmo do risco de base em função da variável binária para o tipo de animal

\begin{tabular}{|c|c|c|}
\hline Variáveis & Estimativa dos parâmetros & Valores de $\mathrm{t}$ \\
\hline Constante & 4,7908 & 46,80 \\
\hline Tipo & $-3,5925$ & $-24,81$ \\
\hline 0,96552 & Estatística F. F $(1,22)$ & $615,9833[.000]$ \\
\hline $\mathrm{R}^{2}$ Ajustado 0,96395 & & \\
\hline
\end{tabular}

Fonte: Elaboração própria. 


\subsection{Análise da Eficiência do Mercado Futuro do Boi Gordo na BM\&F-Bovespa}

Um dos principais pressupostos para a aplicação da metodologia de Myers e Thompson (1989) é que o mercado futuro em questão deve ser considerado eficiente. Para isso, faz-se necessário que as séries utilizadas sejam estacionárias em sua primeira diferença, sendo um processo autorregressivo de primeira ordem, $\mathrm{AR}(1)$, e que a constante e a tendência linear não sejam estatisticamente significativas, conforme já ressaltado. Os resultados se encontram na Tabela 10.

Tabela 10 - Resultados da regressão em primeira diferença contra uma constante e tendência

\begin{tabular}{lll}
\hline Preço à vista do boi gordo (processo em primeira diferença) & \\
\hline Variáveis & Estimativa dos parâmetros & Valores de t [p] \\
\hline Constante & 1,3258 & $0,85615[.392]$ \\
Tendência & 0,0041 & $0,072674[.942]$ \\
\hline Preço futuro do boi gordo (processo em primeira diferença) & \\
\hline Variáveis & Estimativa dos parâmetros & Valores de t [p] \\
\hline Constante & 1,2854 & $0,64855[.517]$ \\
Tendência & 0,0043 & $0,059749[.952]$ \\
\hline
\end{tabular}

Fonte: Elaboração própria.

Conforme a Tabela 10, a constante e a tendência, em ambos os processos, não são estatisticamente significativas nem mesmo ao nível de significância de $25 \%$, ou seja, essas duas variáveis não são estatisticamente importantes no ajuste do modelo de regressão. Esse resultado era esperado, visto que é necessário para haver a possibilidade de eficiência no mercado futuro analisado.

Realizados os testes recomendados para testar a eficiência do mercado, parte-se para o cálculo da razão ótima do hedge e do cross-hedge, de acordo com a metodologia proposta na seção 3 .

\subsection{A Razão Ótima de Hedge e Cross-Hedge}

A equação 25 é utilizada para o cálculo da razão ótima do hedge e cross-hedge para todas as séries de preços. Conforme ressaltado anteriormente, o coeficiente h é interpretado como a razão ótima de hedge e do cross-hedge. Verifica-se que tanto para o hedge, quanto para o cross-hedge, todas as variáveis - com exceção da constante - são significativas a $1 \%{ }^{19}$ (ver Tabela 11).

$19 \quad$ Apesar de a constante não ser significativa, esse fato não traz nenhum prejuízo à análise da razão ótima de hedge e de cross-hedge, já que a única variável importante é o coeficiente $\delta$, que se mostrou significativo tanto para o boi gordo quanto para o bezerro. 
Tabela 11 - Resultado da equação (25) por MQO para obtenção da razão ótima de hedge e de cross-hedge

\begin{tabular}{|c|c|c|}
\hline \multicolumn{3}{|c|}{ Razão ótima de hedge (boi gordo) } \\
\hline Variáveis & Valores estimados & Valores de $\mathrm{t}[\mathrm{p}]$ \\
\hline Constante & 0,30248 & $0,76129[.447]$ \\
\hline Razão ótima (h) & 0,45313 & $23,4685[.000]$ \\
\hline$\Delta P_{t-1}$ & 0,21724 & $5,3521[.000]$ \\
\hline$\Delta P_{t-2}$ & $-0,14676$ & $-5,0379[.000]$ \\
\hline$\Delta F_{t-1}$ & 0,27869 & 10,1977[.000] \\
\hline \multicolumn{3}{|c|}{ Estat. F. $F(4,462) 330,3015[.000]$} \\
\hline \multicolumn{3}{|c|}{ Razão ótima de cross-hedge (bezerro) } \\
\hline Variáveis & Valores estimados & Valores de $\mathrm{t}[\mathrm{p}]$ \\
\hline Constante & 0,17994 & $0,97489[.330]$ \\
\hline Razão ótima (h) & 0,043110 & $4,9178[.000]$ \\
\hline$\Delta P_{t-1}$ & 0,31433 & $6,8700[.000]$ \\
\hline$\Delta P_{t-2}$ & 0,15873 & $3,3801[.001]$ \\
\hline$\Delta P_{t-3}$ & 0,13709 & $3,0778[.002]$ \\
\hline$\Delta F_{t-1}$ & 0,030439 & $3,3641[.001]$ \\
\hline$F(5,460)$ & & \\
\hline
\end{tabular}

Fonte: Elaboração própria.

Sendo o coeficiente $h$ significativo ao nível de confiança de $99 \%$, pode-se utilizá-lo como medida da razão ótima de hedge e cross-hedge. A magnitude desse coeficiente para o hedge do boi gordo é de $45,31 \%$, Assim, para a maior redução possível no risco de preços, é necessário que $45,31 \%$ do total dos contratos possuídos pelo hedge sejam protegidos, via operações de hedge, no mercado futuro de boi gordo da BMËF-Bovespa.

Quanto ao cross-hedge, observa-se uma razão ótima muito baixa (4,31\%), isto é, apenas $4,31 \%$ do montante total de contratos de bezerros possuídos pelo agente devem estar protegidos através de operações de compra de contratos futuros de boi gordo na BMEF-Bovespa.

A diferença entre as razões de hedge e cross-hedge no período de safra e entressafra é estimada através da equação 26 . Nota-se que a variável dummy não se mostrou estatisticamente significativa, apontando a não existência de diferença 
nos preços desse produto entre os períodos de safra e entressafra. Já em relação ao cross-hedge do bezerro, a variável dummy se mostrou estatisticamente significativa, apenas quando considerado um nível de significância maior que 6\%. Portanto, considerando esse nível de significância, a razão ótima do cross-hedge do bezerro é de $7,35 \%$, para o período de safra, e 3,49\% para o período de entressafra. Nesse sentido, deve-se fazer um cross-hedge de $7,35 \%$ da produção durante o período de safra para poder obter a melhor efetividade do cross-hedge, enquanto que na entressafra é necessário proteger apenas 3,49\% da produção.

Tabela 12 - Resultado da equação 26 para obtenção da razão ótima de hedge e de cross-hedge considerando o período de safra e entressafra

\begin{tabular}{|c|c|c|}
\hline \multicolumn{3}{|c|}{ Razão ótima de hedge (boi gordo) } \\
\hline Variáveis & Estimativa dos parâmetros & Valores de $t[\mathrm{p}]$ \\
\hline Constante $(\alpha)$ & 0,30717 & $0,77355[.440]$ \\
\hline Razão ótima $(\delta$ ) & 0,46943 & $20,2217[.000]$ \\
\hline$\Delta P_{t-1}$ & 0,21609 & 5,3259[.000] \\
\hline$\Delta P_{t-2}$ & $-0,14481$ & - 4,9671[.000] \\
\hline$\Delta F_{t-1}$ & 0,27861 & $10,2014[.000]$ \\
\hline$D_{i} \Delta F_{t}$ & $-0,049959$ & $-1,2629[.207]$ \\
\hline Estat. F. $F(5,461)$ & $264,9005[.000]$ & \\
\hline \multicolumn{3}{|c|}{ Razão ótima de cross-hedge (bezerro) } \\
\hline Variáveis & Estimativa dos parâmetros & Valores de $t[\mathrm{p}]$ \\
\hline Constante $(\alpha)$ & 0,15872 & $0,86062[.390]$ \\
\hline Razão ótima $(\delta)$ & 0,034913 & $3,5680[.000]$ \\
\hline$\Delta P_{t-1}$ & 0,31200 & 6,8348[.000] \\
\hline$\Delta P_{t-2}$ & 0,14886 & $3,1585[.002]$ \\
\hline$\Delta P_{t-3}$ & 0,13548 & $3,0492[.002]$ \\
\hline$\Delta F_{t-1}$ & 0,030040 & $3,3281[.001]$ \\
\hline$D_{i} \Delta F_{t}$ & 0,038671 & $1,8653[.063]$ \\
\hline$F(6,459)$ & $45,6174[.000]$ & \\
\hline
\end{tabular}




\subsection{Cálculo da Efetividade do Hedge e do Cross-Hedge}

Realizado os cálculos da razão ótima de hedge e cross-hedge, ou seja, definido o percentual necessário de contratos futuros de boi gordo que deve ser negociado para reduzir os riscos de variação de preço, parte-se, finalmente, para o cálculo da efetividade dessas operações. As efetividades do hedge e do cross-hedge servem como parâmetro do percentual do risco de preço que pode ser reduzido através dessas operações no mercado futuro da BMËF-Bovespa.

Como a variável dummy, calculada na subseção anterior, não se mostrou significativa para o boi gordo, a efetividade do hedge é calculada sem a presença da mesma. Já para o bezerro, calcula-se a efetividade não a considerando num primeiro momento e depois incorporando-a ao modelo de regressão. Os valores obtidos através das simulações realizadas estão disponíveis na Tabela 13.

Tabela 13 - Cálculo da efetividade de hedge do boi gordo e cross-hedge do bezerro da equação 27

\begin{tabular}{cccc}
\hline $\begin{array}{c}\text { Efetividade do hedge } \\
\text { do boi gordo }\end{array}$ & \multicolumn{3}{c}{ Efetividade do cross-hedge do bezerro } \\
\hline Geral & Geral & Safra & Entressafra \\
\hline $69,56 \%$ & $14,29 \%$ & $23,62 \%$ & $11,68 \%$ \\
\hline
\end{tabular}

Fonte: Elaboração própria.

Como pode ser visualizado, o hedge geral do boi gordo se mostrou bastante efetivo como forma de proteção contra os riscos de preços, pois possibilita proteger o produtor contra cerca de $70 \%$ dos riscos provenientes das variações dos preços. Já a efetividade de cross-hedge não foi tão significativa, sendo para o período de safra o valor mais representativo, mostrando que apenas 23,62\% dos riscos de preço podem ser dissipados utilizando a estratégia de cross-hedge. Apesar de pouco significativa, ela é representativa quando se considera que, para obter essa efetividade, é necessário fazer operações de cross-hedge para apenas 7,35\% do número de bezerro possuídos pelo produtor.

\section{Considerações Finais}

A atividade agropecuária, assim como todas as outras atividades que necessitam de um determinado intervalo de tempo entre o ato de investir e o momento de auferir os lucros, sofre riscos durante o prazo de maturação desse investimento. Neste estudo em especial, dedicou-se apenas à análise dos riscos provenientes dos preços - que possuem grande importância nessa atividade, em todos os diferentes níveis da cadeia de produção. Assim, procurou-se averiguar se o mercado futuro de commodities fornece uma boa ferramenta de proteção para os produtores de

FREITAS, C. A.; ALVES, W. B. Análise da Efetividade e da Razão Ótima do Hedge do Boi... 
boi gordo e bezerro contra esses riscos de preços. Para alcançar esse propósito, estimou-se o risco de base, a efetividade, a razão ótima de hedge e do cross-hedge, como forma de mensurar o risco de preço, calculou-se o risco de base para o boi gordo e o bezerro.

Os resultados retrataram um risco muito mais elevado para o cross-hedge do bezerro do que para o hedge do boi gordo. Essa constatação parece óbvia quando se compara o risco de se operar com dois ativos de natureza distinta, pois, apesar de serem atividades complementares, não necessariamente sofrem a mesma influência das variáveis externas relacionadas a essas respectivas atividades.

Já com relação à razão ótima de hedge (cross-hedge) e à efetividade para ambos os animais, obteve-se uma razão ótima para o hedge do boi gordo mais elevada do que para o cross-hedge. Isso mostra que, para os criadores de boi, foi necessária uma maior utilização de operações no mercado futuro, vis-à-vis os criadores de bezerro, para uma gestão mais eficiente dos riscos de preços. Porém, ao analisar a efetividade dessas operações, verificou-se que a proteção alcançada para o boi gordo pode ser considerada boa e muito superior à do bezerro, sendo a do boi gordo cerca de $70 \%$ contra apenas $14 \%$ do bezerro.

Para verificar se havia alguma diferença de razão ótima e efetividade entre os períodos de safra e entressafra, utilizou-se uma variável dummy. Esta, por sua vez, mostrou-se significativa apenas para o cross-hedge, não havendo diferenças significativas relacionadas ao preço do boi gordo. Analisando a razão ótima e a efetividade do cross-hedge, obteve-se uma necessidade de negociação de um percentual maior da quantidade de bezerro possuída pelo produtor durante o período de safra ante ao período de entressafra. Assim como a efetividade, a razão ótima também se mostrou mais elevada para o período de safra frente ao de entressafra, mostrando que os preços são mais previsíveis e seus riscos mais fáceis de serem controlados durante o período em que a oferta de bezerro é maior.

Analisando os resultados alcançados, pode-se afirmar que os produtores de boi possuem, na estratégia de hedge, uma boa ferramenta para proteção contra os riscos de preços de seu ativo comercializado, porém, para proteção na reposição de seus estoques - compra de bezerro para engorda - estes ficam à mercê das intempéries do mercado. Os criadores de bezerro, por sua vez, não possuem um instrumento eficaz no mercado futuro para sua proteção.

Dessa forma, ressalta-se a necessidade de criação de um instrumento mais alinhado às necessidades dos criadores de bezerro, para que estes possuam um meio de diminuir - e melhor gerenciar - os riscos existentes em suas atividades, tornando possivel, assim, além dos benefícios para os produtores de bezerro, a possibilidade de proteção nas duas pontas de sua atividade - compra de bezerro e venda de boi gordo - por produtores de boi. 
Tendo como pano de fundo os resultados alcançados com o presente estudo, essa temática pode avançar em algumas vertentes. Primeiro, sugere-se atualizar, para ambos os animais, a base de dados e replicar o estudo para as mesmas praças. Isso permitirá comparar os resultados tanto da razão ótima quanto para efetividade do hedge e do cross-hedge em diferentes momentos do tempo. Segundo, replicar tais procedimentos em outros locais de comercialização do bezerro e boi gordo, dentro do país. Os resultados alcançados irão revelar se alterando essas praças de comercialização obtêm-se mudanças estatisticamente significativas da razão ótima do hedge e do cross-hedge. Terceiro, avaliar se as bolsas internacionais, como a Chicago Board of Trade (CBOT), por exemplo, são uma opção viável para as estratégias de hedge por parte dos agentes brasileiros como opção para a minimização de riscos nas atividades do boi gordo e do bezerro.

Finalmente, cabe ressaltar a existência de outros modelos que podem ser utilizados para o gerenciamento de risco no processo de comercialização das commodities agropecuárias, como modelo de autorregressão vetorial (VAR), modelo da família heterocedasticidade condicional autorregressiva (ARCH). Contudo, para vários autores, ${ }^{20}$ nenhuma dessas ferramentas se apresenta mais eficiente no gerenciamento de risco de preços e na análise das operações de hedge de commodities agropecuárias do que o modelo aqui estimado proposto por Myers e Thompson (1989).

\section{Referências}

BITTENCOURT, W. A.; SILVA, W. S.; SAFÁDI, T. Hedge dinâmicos: uma evidência para os contratos futuros brasileiros. Organizações Rurais e Agroindustriais, Lavras, v. 8, n. 1, p. 71 $78,2006$.

EDERINGTON, L. H. The hedging performance of the new futures markets. Journal of Finance, v. 34, n. 1, p. 157-170, 1979.

ENDERS, W. Applied econometric time series. 3. ed. New York: John Wiley E Sons, 2010.

FONTES, R. E. et al. Estratégia de comercialização em mercados derivativos: descobrimento de base e risco de base da cafeicultura em diversas localidades de Minas Gerais e São Paulo. Revista Ciência e Agrotecnologia, Lavras, v. 29, n. 2, p. 382-389, mar./abr. 2005.

GONÇALVES, D. F. et al. Co-integração, causalidade e efetividade do hedge para preços do contrato de boi gordo para noroeste do Paraná. Informe Gepec, v. 12, p. 11-25, 2008.

GUJARATI, D. Econometria básica. Rio de Janeiro: Elsevier, 2006.

JOHNSON, L. L. The theory of hedging and speculation in commodity futures markets. Review Economic Studies. v. 27, p. 139-151, 1960.

MARKOWITZ, H. Portfolio selection. The Journal of Finance, v. 7, n. 1, p. 77-91, 1952.

$\overline{20} \quad$ A saber: Bittencourt, Silva e Sáfadi (2006), Müller (2007) e Oliveira Neto e Figueredo (2009). 
MÜLLER, C. A. S. Análise da efetividade das estratégias estáticas e dinâmicas de hedge para o mercado brasileiro de café arábica. 2007. 132 f. Tese (Doutorado em Economia Aplicada) Universidade Federal de Viçosa, Viçosa, MG, 2007.

MYERS, R. J.; THOMPSON, S.R. Generalized optimal hedge ratio estimation. American Journal of Agricultural Economics, v. 71, n. 4, p. 858-867, nov. 1989.

OLIVEIRA, A. R. et al. Um estudo dos principais aspectos produtivos e mercadológicos da pecuária de corte brasileira. In: CONGRESSO BRASILEIRO DE ECONOMIA, ADMINISTRAÇÃO E SOCIOLOGIA RURAL, 2006, Fortaleza. Anais... Fortaleza: SOBER, 2006. 1 CDRom.

OLIVEIRA NETO, O. J.; FIGUEIREDO, R. S. Efetividade das operações de hedge do boi gordo no mercado futuro da BMËF para o Estado de Goiás. Conjuntura Econômica Goiana, v. 12, p. 73-86, 2009.

SABOYA, L. V.; BACCHI, M. R. P. Uma proposta metodológica para a análise da eficiência na formação de preços de contratos futuros. In: CONGRESSO BRASILEIRO DE ECONOMIA, ADMINISTRAÇÃO E SOCIOLOGIA RURAL, 1999, Foz do Iguaçu. Anais... Foz do Iguaçu: SOBER, 1999. 1 CD-ROM.

SCHOUCHANA, F.; CAFFAGNI, F. S. Fatores que determinam o preço do bezerro. Resenha $B M E F$, n. 143, p. 67-75, 2001.

SHARPE, W. F. Capital asset prices: A theory of market equilibrium under conditions of risk. The Journal of Finance, v. 19, n. 3, p. 425-442, 1964.

SILVA, A. R. O. A efetividade do hedge e do cross-hedge de contratos futuros para soja e derivados. Viçosa, 2001. Dissertação (Mestrado em Economia Rural) - Universidade Federal de Viçosa, 2001.

SILVEIRA, R. L. F. Análise das operações de cross-hedge do bezerro e do hedge do boi gordo no mercado futuro da BMËF. Piracicaba, 2002. Dissertação (Mestrado Economia Aplicada) - Escola Superior de Agricultura "Luiz de Queiroz", Universidade de São Paulo, 2002.

TONIN, J. M.; BRAGA, M. J.; COELHO, A. B. Efetividade de hedge do milho com contratos futuros da BMËF: uma aplicação para a região de Maringá, PR. Revista de Economia, v. 35, p. 1-12, 2009.

Recebido em: 09/08/2011.

Aceito em: 24/03/2013. 